while agreeing that in certain instances single-frame strip $(18 \mathrm{~mm}$. $\times 24 \mathrm{~mm}$.) will continue to be used.

There is still a tendency in many quarters to regard cinematograph film as almost the only form of visual aid worth mentioning. Ciné-film will always play an important part in education, but for regular classroom use the more humble filmstrip has much to commend it. The apparatus required is compact, weighs little and is easy to operate. The medium can be adapted to most classroom needs, is economical of time and allows considerable control of material by the user. Further, at very moderate cost the teacher can try out his own ideas in the way of filmstrip production-and will learn much in the process. Users of filmstrip, whether or not they are interested in amateur production, will find the practical suggestions in this little book helpful and stimulating without being dogmatic.

ERIC Lowe

The Artificial Insemination of Farm Animals

By John W. Bartlett, George E. Taylor, Joseph Edwards, Clair E. Terrill, Victor Berliner and Fred P. Jeffrey. Enos J. Perry, Editor. Pp. v+265. (London : Chapman and Hall, Ltd., 1947.) 15s. net.

HIS book originally appeared in the United States in 1945. Since then much practical experience has been gained in the application of artificial insemination, both in the United States, where some million and a half cows are by now being registered annually for insemination, and in Britain, where a network of insemination centres will soon cover the country. Research work stimulated by this rapid advance has also made considerable progress, and improvements in method are continually being adopted. Quite new problems are arising. Although in consequence of this rapid advance this English edition is in many respects already out of date, it is still the most comprehensive work on the subject in the English language, and will prove very useful as a general introduction for the student of agriculture and veterinary science and for the farmer who takes an interest in the advance of scientific method. To the specialist it will be rather less useful. The treatment is on broad general lines, and exact quantitative data are not usually given to support the arguments. The chapters which describe the technical aspects are the most important. The ones which deal with the genetical aspects of livestock improvement are of less value. Arthur WaLton

\section{Forest Valuation}

With Special Emphasis on Basic Economic Principles. By Prof. Herman H. Chapman and Prof. Walter H. Meyer. (American Forestry Series.) Pp. xii+521. (New York and London : McGraw-Hill Book Co., Inc., 1947.) $36 s$.

7 HIS book represents the development of earlier work on valuation and finance by Prof. Chapman of Yale. The wide scope of the applied part can be inferred from the main contents : the evaluation of real property producing annual income; present worth of forests producing periodic income; costs of production versus profits and the role of compound interest; rates earned and the profit margin; rotations; taxation; damages; fire insurance; methods of appraisal of stumpage value; determination and application of conversion returns; and the appraisal of forestry purchases for future operations. Appropriate formulæ, mainly concerned with compound interest and discount, are provided for the many and various problems which arise in forest finance. The importance of discount as applied to future net income in determining the present worth of an enterprise is stressed. Market values have limitations, and confusion in the past has been caused by the limitations in the use of compound interest. The authors hope that their treatment marks the final departure from the original European sources of forest evaluation and statics as set forth in Schlich's "Manual of Forestry". Many of the problems illustrated in the book are therefore specifically North American, although the principles outlined have wide applicability.

Teachers of applied economics will be interested to note the emphasis on the great advantage to students of a grounding in economic theory. The first six chapters have this need in mind, and the hope is that by stressing these principles in their direct relation to forest economics and valuation, the subject has been vitalized and its importance made clear to professional foresters and to owners and operators of forest property.

J. J. MacGregor

\section{Le forze creatrici dell'uovo}

Questioni moderne d'embriologia. Per Prof. Pasquale Pasquini. (Sapienza, Vol 3.) Pp. 334. (Pisa and Rome : Libreria Vallerini, 1948.) 700 lire.

DROF. P. PASQUINI has provided Italian readers with a clear and well-illustrated introduction to moderm experimental embryology. He opens with a historical chapter, in which the seventeenth-century controversy between epigenesis and preformation gives him an opportunity to define the fundamental problems. The next chapter, on the maturation of the gametes, gives a good, if elementary, account of the cytoplasmic organisation of the ovum; but, as so often in embryological works, is old-fashioned in its treatment of meiosis. After these preliminaries, we come on to experimental embryology proper. Although there is nothing very original in the author's treatment, he covers the ground adequately, bringing his book right up to date by accounts of such new developments as Holtfreter's studies on the mechanism of gastrulation and the various theories of organiser action. The Italians are fortunate in having such a text-book for university students in their early years; there is nothing similar available in Great Britain.

C. H. W.

\section{Bird Recognition}

1: Sea-Birds and Waders. By James Fisher. (Pelican Books, A.175.) Pp. 190. (Harmondsworth and New York: Penguin Books, Ltd., 1947.) 2s. 6d.

A LI, too often the elaborate descriptions of birds A that give each detail of plumage with minute exactitude are not much help to recognition in the field. Mr. James Fisher, in a 'Pelican' devoted to sea-birds and waders, and entitled "Bird Recognition", writes not with one eye but with both eyes on the field worker, and the novice at that. All persons interested in ornithology will find this little volume helpful but no one more so than the beginner, who will find it a valuable aid to the identification of the many species of waders and gulls to be found on and near the sea. The illustrations consist of monochrome portrait sketches by "Fish-hawk", maps chiefly by Mr. W. B. Alexander, and diagrams, consisting of circular calendars, showing the distribution of the species throughout the twelve months. Much information is thus packed into a small space and a useful, helpful book results.

Frances Pitt 